\title{
Parametric Optimization of the Output Shaft of a Portal Axle using Finite Element Analysis
}

\author{
Jong Boon Ooi ${ }^{1}$ - Xin Wang2,* - Ying Pio Lim ${ }^{1}$ - ChingSeong Tan ${ }^{3}$ - Jee-Hou Ho ${ }^{4}$ - Kok-Cheong Wong 4 \\ 1Universiti Tunku Abdul Rahman, Faculty of Engineering and Science, Malaysia \\ ${ }^{2}$ Monash University Malaysia, School of Engineering, Malaysia \\ ${ }^{3}$ Multimedia University, Faculty of Engineering, Malaysia \\ ${ }^{4}$ University of Nottingham Malaysia Campus, Faculty of Engineering, Malaysia
}

\begin{abstract}
A portal axle unit is a gearbox unit installed on a vehicle for higher ground clearance and driving in off-road conditions. Shafts must be exceptionally tough and light to improve the overall performance of the portal axle unit. In this paper, a hollow shaft with a rib at both ends was proposed. The torsional stress of the three-dimensional shaft model was determined using finite element analysis (FEA) and validated by experimental testing. The hollow shaft thickness, rib thickness, depth of spokes, rib fillet radius, and number of spokes are the five of parameters considered in the torsional strength analysis of the rib. A Taguchi orthogonal array (L25) was applied to determine the optimum set of parameters for the proposed shaft. The strength and weight of the optimized model were calculated and compared to the solid shaft, hollow shaft, and proposed model. The optimized model showed improvement in torsional strength with a slight increase in weight compared to the benchmark model.
\end{abstract}

Keywords: parametric optimization, finite element analysis, shaft design, portal axle

\section{INTRODUCTION}

A portal axle unit is a gearbox unit installed on vehicle for higher ground clearance and driving in off-road conditions. Fig. 1 shows the difference between normal vehicle and vehicle with portal axle. In the event of driving off road, the operating portal axles are frequently subjected to shock, and overloading may eventually lead to failure shafts. Therefore, shafts in the portal axle must be designed with exceptionally high strength and be lightweight for improved reliability and performance.

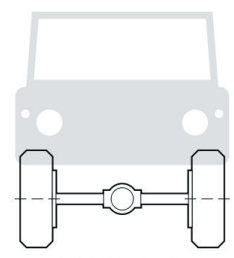

NORMAL AXLE

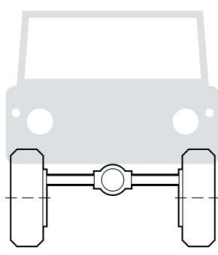

PORTAL AXLE
Fig. 1. Difference between normal axle and portal axle

In most portal axle gearboxes, hollow gear shafts with acceptable thickness are normally manufactured to achieve a higher strength-to-weight ratio. However, extremely high torsion and cyclic loading resulting from driving off-road may cause higher fatigue failure or complete shaft breakage [1]. Torsional, bending and normal forces occur during the working of the shaft [2]. There is evidence of failure in the shaft due to many factors. Heyes [3] studied the common failure types in automobiles and revealed that the failure in the transmission system elements cover a quarter of all the automobile failures. Vogwell [4] carried out a study on a failed axle and obtained the stresses on the axle via a numerical analysis technique. Other failure parts such as the failure on planetary gear wear were investigated by Yüksel and Kahraman [5] and the failure of the swing pinion shaft were investigated by Ranganath et al. [6].

Shaft designers and engineers are constantly finding solutions for redesigning shaft based on parameters to achieve an improved strength-to-weight ratio. However, they often investigate the effect of a single factor to the shaft strength and obtain the relationship. Investigating one factor at a time can be less effective, because other parameters that are considered may be interdependent and affect the overall shaft strength. Even though there are shaft design standards [7] to [9] such as the American National Standards Institute (ANSI) and the American Society of Mechanical Engineers (ASME) that can be used as a guide for engineers, they are often too general to be applied for specific applications. This is because design standards are limited to certain design criteria and design parameters for shafts. In the case of designing shafts for a portal axle gearbox, it is necessary to propose a customized shaft design for extreme operating conditions. In this paper, a hollow shaft with a rib at both ends is proposed. The hollow shaft thickness, rib thickness, rib fillet radius, depth of spokes and number of spokes of the rib structure are the quantitative parameters considered for the proposed hollow shaft. Fig. 2 shows the schematic 
flow diagram of the steps for optimizing the proposed shaft model through parametric analysis.

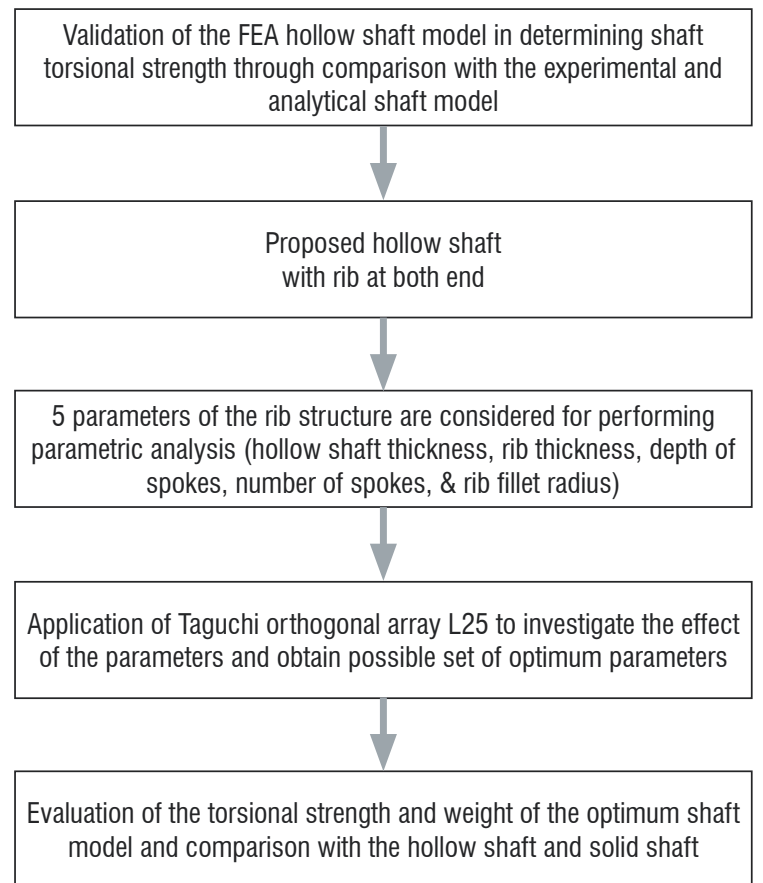

Fig. 2. Schematic flow diagram for obtaining the optimum set of parameters of the hollow shaft with rib

ANSYS v12 software is used to investigate the torsional stress behaviour of the shaft. The FEA is a widely accepted numerical method in evaluating and verifying shaft design [10]. Recently, the gearbending stress and contact stress of the gears of the portal axle gearbox has been analysed using FEA [11]. Göksenli and Eryürek [12] used the FEA program to simulate stress analysis on the keyway shaft of an elevator to verify their mathematical calculations for determining the maximum stress. Bayrakceken et al. [13] determined the stress conditions of the failed section at the universal joint yoke of the shaft using FEA program.

Recently, the use of Taguchi method has been proven effective in the work related to optimizing flow stress input for machining simulation [14]. In this paper, the L25 Taguchi orthogonal array is applied to investigate the five different parameters that may affect the shaft strength. This method is also applied to investigate the sensitivity of the five parameters to the torsional strength of the hollow shaft with the rib and to determine the possible set of optimum parameters. The strength and weight of the optimised model are obtained and compared with the solid shaft, hollow shaft, and proposed shaft.

\section{VALIDATION OF THE FEA SHAFT MODEL}

\subsection{Finite Element Analysis}

ANSYS v12.0 software is used to determine the maximum torsional stress of the shaft. Firstly, a threedimensional hollow shaft $3 \mathrm{~mm}$ thick, $210 \mathrm{~mm}$ long and $37 \mathrm{~mm}$ in diameter is modelled. The surface boundary conditions are applied to the shaft model as shown in Fig. 3. Fixed support is applied at one end shaft and $100 \mathrm{Nm}$ of torsion is applied on the other end of the shaft.

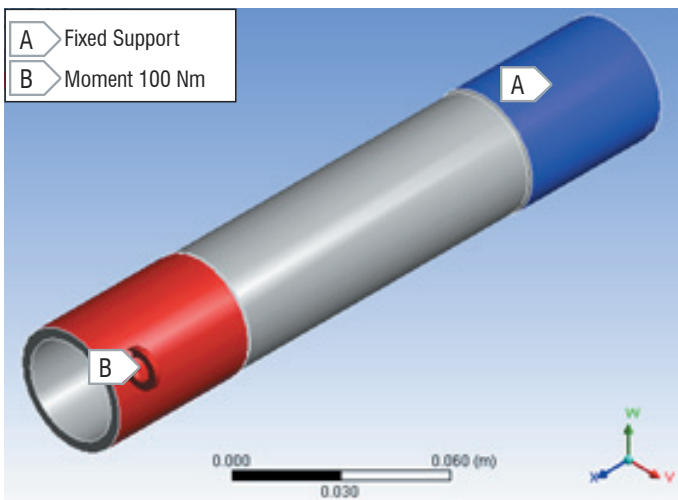

Fig. 3. Applied load and constraint on the hollow shaft

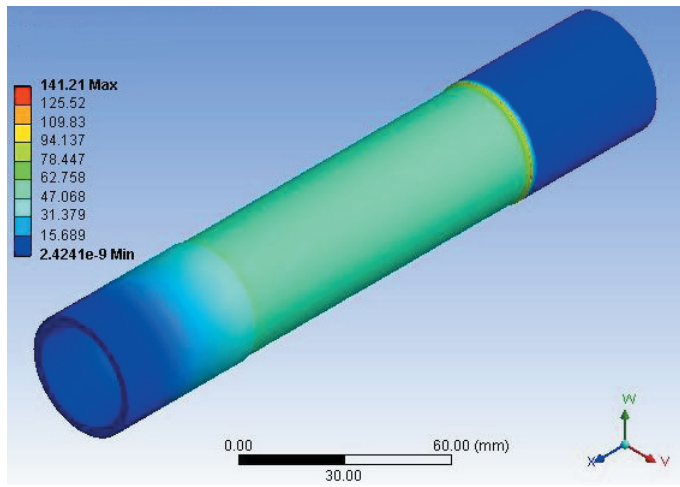

Fig. 4. FEA simulation of the von Mises stress of the hollow shaft

In the mesh settings, four nodes and a linear tetrahedron type element are selected to mesh the shaft model. The average element size was set to 5 $\mathrm{mm}$ in the mesh settings.

The maximum von Mises stress (torsional stress) of the hollow shaft model calculated in ANSYS is 141.21 MPa.

\subsection{Analytical Method}

Distortion energy theory (DET) is applied to determine the von Mises stress of the hollow shaft. DET (also known as the von Mises criterion) postulates that 
failure is caused by the elastic energy associated with shear deformation. The hollow shaft is assumed to be ductile material, thus DET is valid and can be applied. DET considers the maximum axial stress in the transverse direction (perpendicular to the shaft axis) caused by the bending moment and the maximum shear stress caused by torque. For a hollow shaft, the maximum axial stress is:

$$
\sigma_{x}=\frac{32 M D}{\pi\left(D^{4}-d^{4}\right)} .
$$

Similarly, the maximum shear stress is:

$$
\tau_{x y}=\frac{16 T D}{\pi\left(D^{4}-d^{4}\right)},
$$

where $M$ is the bending moment, $T$ is the applied torque, $D$ is the external diameter of the hollow shaft, and $d$ is the internal diameter of the hollow shaft. The principal stresses can be determined with the known value of $\sigma_{x}$ and $\tau_{x y}$ as in the following:

$$
\sigma_{1,2}=\frac{\sigma_{x}+\sigma_{y}}{2} \pm \sqrt{\left(\frac{\sigma_{x}+\sigma_{y}}{2}\right)^{2}+\tau_{x y}^{2}} .
$$

For the plane stress state, the principal normal stresses when $\sigma_{y}=0$, are:

$$
\sigma_{1}, \sigma_{2}=\frac{16}{\pi d^{3}}\left(M \pm \sqrt{M^{2}+T^{2}}\right) .
$$

Finally, the general equation for calculating the von Mises stress of the shaft is:

$$
\sigma_{e}=\left(\sigma_{1}^{2}-\sigma_{1} \sigma_{2}+\sigma_{2}^{2}\right)^{\frac{1}{2}} \text {. }
$$

In using the DET for determining the shaft torsional stress, there are few assumptions to be considered:

1. It is based on a two-dimensional schematic diagram.

2. The effect of gravity and the mass of the shaft are neglected.

3. DET is only valid for ductile material.

\subsection{Experiment Test}

In the experiment test, the TiniusOlsen torsion tester is used to apply torsion to the hollow shaft. Firstly, the long rod of normalized AISI 4340 alloy steel with one-and-a- $37 \mathrm{~mm}$ in outer diameter and 3 $\mathrm{mm}$ hollow shaft thickness is cut to a length of 210 $\mathrm{mm}$. The cylindrical surface of the hollow shaft is slightly machined to approximately $37 \mathrm{~mm}$ in outer diameter and for a smoother surface finish by using the computer numerical control $(\mathrm{CNC})$ lathe machine. The hollow shaft is then pre-assembled with a strain gage rosettes that provide shear strain data. When torsion is applied to the shaft, causing it to twist, shear stresses are induced. The stresses are measured by bonding the strain gauges at $45^{\circ}$ to the horizontal torque axis. Fig. 5 shows the bonding of the strain gauge on the hollow shaft.

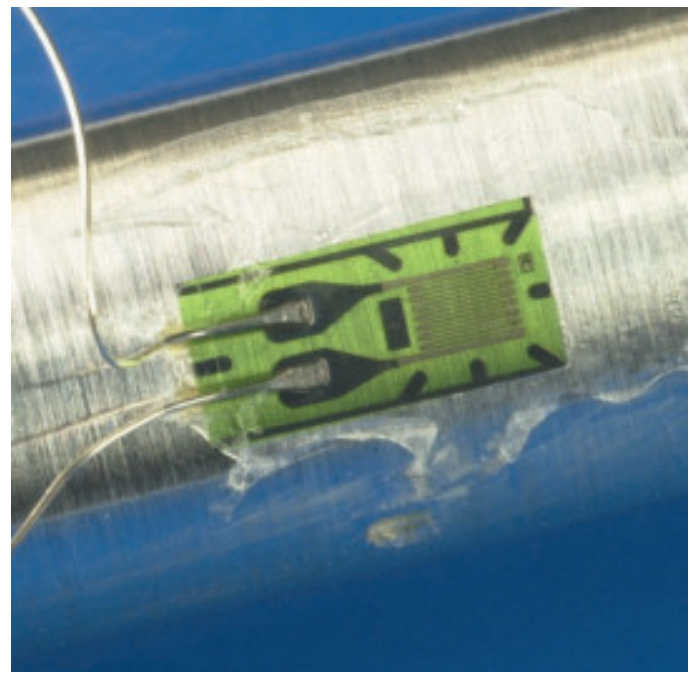

Fig. 5. Bonding of the strain gauge at the centre of the shaft

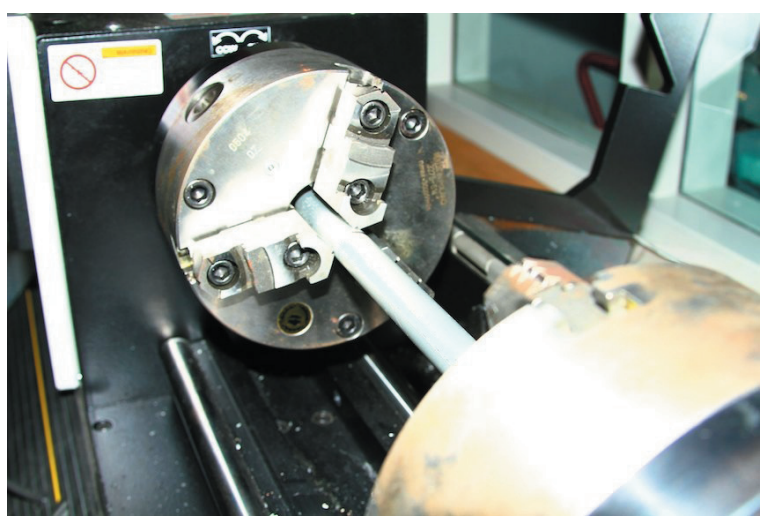

Fig. 6. Mounting of the shaft to the TiniusOlsen torsion testing machine

Fig. 6 shows the mounting of the hollow shaft on the Tinius Olsen torsion tester. Both ends of the shaft are gripped and tightened using the jaw and chuck. This machine comes with a built-in data acquisition system in which the computer retrieves all the measured data required. The LabView program reads all data and writes to a text file that is readable into Microsoft Excel spreadsheet. 


\subsection{Comparison of the FEA model with the experimental and analytical model}

The FEA model is compared with the experimental and analytical model. With the same size and dimension of the solid shaft, the torsional stresses of the models are plotted against the increasing torque, as shown in Fig. 7. All models show linear relationship when torsional stress is plotted against the linear increment of torque. The experimental model has higher torsional stress compared to the FEA and the analytical model. However, the torsional stress calculated for the FEA model is quite close to the torsional stress measured from the experimental model. The average percentage of difference between them is only $9.83 \%$. This shows the FEA model agrees well with the experimental model. The huge difference between the analytical model with the FEA and experimental models is due to the consideration of the shaft analysis of the shaft in one dimension, and many assumptions are made to perform the calculations.

\section{PARAMETRIC OPTIMIZATION OF THE HOLLOW SHAFT WITH RIB}

\subsection{Modelling of the Hollow Shaft with Rib}

A hollow shaft with a rib at both ends is proposed for the output shaft of the portal axle. The proposed shaft with five parameters is modelled, as shown in Fig. 8. Table 1 shows the material properties and the dimensions used for modelling the shaft. The proposed shaft is used as a benchmarking shaft for comparison with the optimized shaft and the hollow shaft in later section. Similarly, the proposed model of the hollow shaft with a rib, a torque of $100 \mathrm{Nm}$ is applied at one end of the shaft and the other end of the shaft is fixed. In Fig. 9, the von Mises stress determined in the ANSYS FEA software is $102.72 \mathrm{MPa}$.

\subsection{Parametric Optimization}

The L25 Taguchi orthogonal array (OA) is applied to determine the optimum combination of the five parameters (the hollow shaft thickness, rib thickness, depth of spokes, rib fillet radius, and the number of spokes) that will result in the lowest torsional stress. These parameters are set in the $\mathrm{DOE}++$ software. The parametric design of the shaft is set with five different factors ( 5 parameters) and five levels (5 variables) as shown in Table 2. In Table 3, 25 unique combination parameters are generated by using DOE++ software. Then FEA simulation is conducted

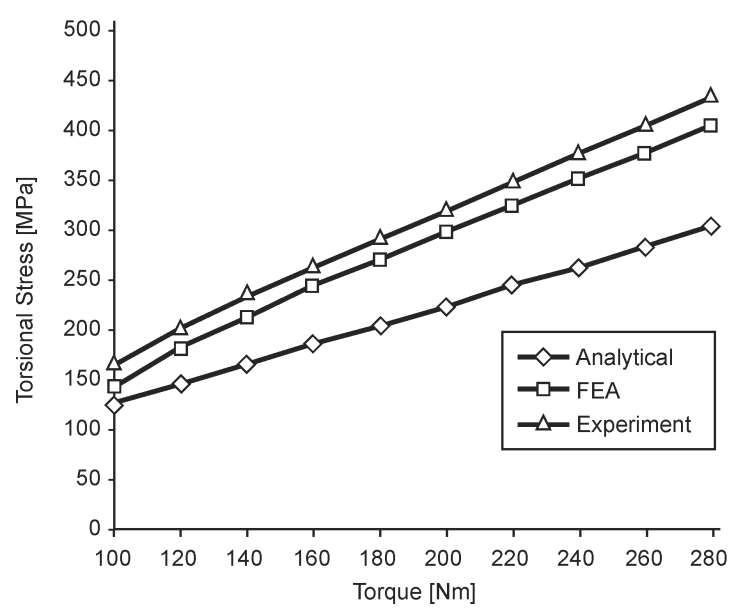

Fig. 7. Comparison between the FEA model, experimental model, and the analytical model by plot of the torsional stress against increasing torque

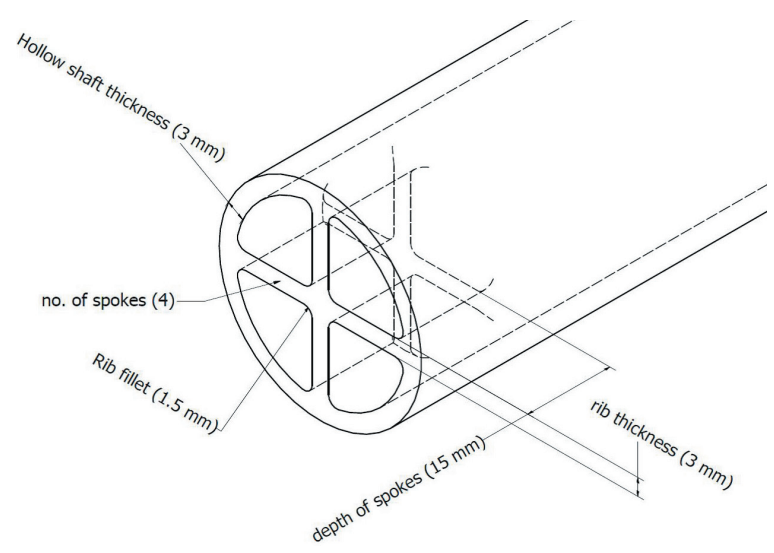

Fig. 8. Model of the hollow shaft with rib and the 5 parameters

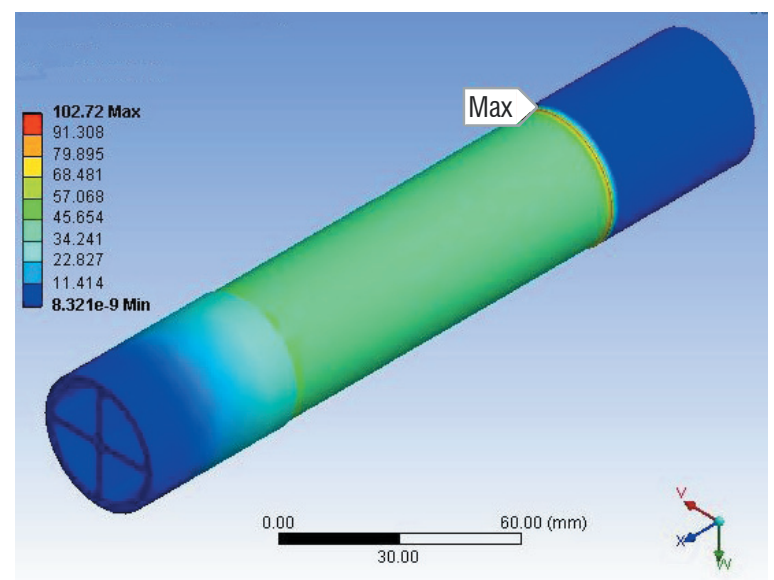

Fig. 9 FEA simulation of the von Mises stress of the hollow shaft with rib

for each combination parameters. Thus, the maximum stress of each combination is obtained by using FEA simulation. 
Table 1. Dimensions and material properties of the proposed shaft model

\begin{tabular}{ll}
\hline Length & $210 \mathrm{~mm}$ \\
\hline Outer diameter & $37 \mathrm{~mm}$ \\
\hline Material & $\begin{array}{l}\text { AlSI } 4340 \text { alloy steel } \\
\text { (normalized at } 870^{\circ} \mathrm{C} \text { ) }\end{array}$ \\
\hline Ultimate tensile stress (UTS) & $1279.0 \mathrm{MPa}$ \\
\hline Tensile yield strength & $861.8 \mathrm{MPa}$ \\
\hline Young's Modulus & $210 \mathrm{GPa}$ \\
\hline Poisson's Ratio & 0.30 \\
\hline Density & $7850 \mathrm{~kg} / \mathrm{m}^{3}$ \\
\hline
\end{tabular}

In the next step, Analysis of Variance (ANOVA) is generated to determine the ' $F$ Ratio' and ' $P$ value' so that the level of significance of the parameters to the output (objective) can be distinguished. Table 4 shows the ANOVA of the five factors and the regression of each factor. In general, the notation of the applied L25 Taguchi array (5 to the power of 6) should consist of six factors in the Taguchi array. Since there are only five factors used in the Taguchi array, the remaining factor from the Taguchi array provides four degrees of freedom for the residual, which is calculated as a difference between the total sum-of-squares and the model's sum-of-squares. The $F$-statistic ( $F$-ratio) for each factor is calculated by taking the mean squares of the factor divided by the mean squares of the residual. A high value of the $F$-statistic of a factor implies that the effect of the factor is relevant and significant. In this case, the hollow shaft thickness contribute to the highest value of $F$-statistic.

Table 2. Factorial design of the shaft model using 5 factors with 5 levels

\begin{tabular}{cllcccccc}
\hline & \multicolumn{1}{c}{ Factor } & Unit & Type & Level 1 & Level 2 & Level 3 & Level 4 & Level 5 \\
\hline A & hollow shaft thickness & {$[\mathrm{mm}]$} & qualitative & 1 & 2 & 3 & 4 & 5 \\
\hline B & rib thickness & {$[\mathrm{mm}]$} & qualitative & 1 & 2 & 3 & 4 & 5 \\
\hline C & depth of spokes & {$[\mathrm{mm}]$} & qualitative & 5 & 10 & 15 & 20 & 25 \\
\hline D & rib fillet radius & {$[\mathrm{mm}]$} & qualitative & 1 & 1.25 & 1.5 & 1.75 & 2 \\
\hline E & no. of spokes & {$[-]$} & qualitative & 2 & 3 & 4 & 5 & 6 \\
\hline
\end{tabular}

Table 3. Taguchi orthogonal array L 25 design factors

\begin{tabular}{|c|c|c|c|c|c|c|c|}
\hline $\begin{array}{l}\text { Standard } \\
\text { order }\end{array}$ & $\begin{array}{l}\text { Run } \\
\text { order }\end{array}$ & $\begin{array}{l}\text { Hollow shaft } \\
\text { thickness [mm] }\end{array}$ & $\begin{array}{l}\text { Rib thickness } \\
{[\mathrm{mm}]}\end{array}$ & $\begin{array}{c}\text { Depth of spokes } \\
{[\mathrm{mm}]}\end{array}$ & $\begin{array}{l}\text { Rib fillet radius } \\
{[\mathrm{mm}]}\end{array}$ & $\begin{array}{l}\text { No. of } \\
\text { spokes }\end{array}$ & $\begin{array}{l}\text { von Mises } \\
\text { stress [MPa] }\end{array}$ \\
\hline 23 & 1 & 5 & 3 & 10 & 1.00 & 6 & 119.1 \\
\hline 13 & 2 & 3 & 3 & 25 & 1.25 & 5 & 215.5 \\
\hline 19 & 3 & 4 & 4 & 10 & 2.00 & 4 & 88.56 \\
\hline 5 & 4 & 1 & 5 & 25 & 2.00 & 6 & 263.6 \\
\hline 24 & 5 & 5 & 4 & 15 & 1.25 & 2 & 109.9 \\
\hline 14 & 6 & 3 & 4 & 5 & 1.50 & 6 & 123.8 \\
\hline 3 & 7 & 1 & 3 & 15 & 1.50 & 4 & 270.4 \\
\hline 2 & 8 & 1 & 2 & 10 & 1.25 & 3 & 293.1 \\
\hline 1 & 9 & 1 & 1 & 5 & 1.00 & 2 & 226.8 \\
\hline 22 & 10 & 5 & 2 & 5 & 2.00 & 5 & 121.2 \\
\hline 8 & 11 & 2 & 3 & 20 & 2.00 & 2 & 206.7 \\
\hline 17 & 12 & 4 & 2 & 25 & 1.50 & 2 & 135.3 \\
\hline 7 & 13 & 2 & 2 & 15 & 1.75 & 6 & 193.8 \\
\hline 25 & 14 & 5 & 5 & 20 & 1.50 & 3 & 92.24 \\
\hline 11 & 15 & 3 & 1 & 15 & 2.00 & 3 & 158.5 \\
\hline 16 & 16 & 4 & 1 & 20 & 1.25 & 6 & 186.0 \\
\hline 18 & 17 & 4 & 3 & 5 & 1.75 & 3 & 132.1 \\
\hline 21 & 18 & 5 & 1 & 25 & 1.75 & 4 & 129.0 \\
\hline 12 & 19 & 3 & 2 & 20 & 1.00 & 4 & 149.7 \\
\hline 10 & 20 & 2 & 5 & 5 & 1.25 & 4 & 194.8 \\
\hline 6 & 21 & 2 & 1 & 10 & 1.50 & 5 & 186.5 \\
\hline 15 & 22 & 3 & 5 & 10 & 1.75 & 2 & 147.3 \\
\hline 4 & 23 & 1 & 4 & 20 & 1.75 & 5 & 229.7 \\
\hline 20 & 24 & 4 & 5 & 15 & 1.00 & 5 & 126.9 \\
\hline 9 & 25 & 2 & 4 & 25 & 1.00 & 3 & 179.4 \\
\hline
\end{tabular}


Table 4. Analysis of variance (ANOVA) of the 5 parameters

\begin{tabular}{lccccc}
\hline \multicolumn{1}{c}{ Source of variation } & Degrees of freedom & Sum of squares [Partial] & Mean squares [Partial] & $F$ ratio & $P$ value \\
\hline Model & 20 & $7.56 \mathrm{E}+04$ & 3780.4376 & 15.2389 & 0.0085 \\
\hline A: hollow shaft thickness & 4 & $6.27 \mathrm{E}+04$ & $1.57 \mathrm{E}+04$ & 63.2162 & 0.0007 \\
\hline B: rib thickness & 4 & 5307.9926 & 1326.9982 & 5.3491 & 0.0666 \\
\hline C: depth of spokes & 4 & 1657.4014 & 414.3504 & 1.6702 & 0.3157 \\
\hline D: rib fillet radius & 4 & 5325.5358 & 1331.384 & 5.3668 & 0.0663 \\
\hline E: no. of spokes & 4 & 587.819 & 146.9548 & 0.5924 & 0.6878 \\
\hline Residual & 4 & 992.3096 & 248.0774 & - & - \\
\hline Lack of fit & 4 & 992.3096 & 248.0774 & - & - \\
\hline Total & 24 & $7.66 \mathrm{E}+04$ & - & & - \\
\hline
\end{tabular}

Table 5. Diagnostic analysis of the $L 25$ design factors

\begin{tabular}{|c|c|c|c|}
\hline Run order & Standard order & Actual value $(\mathrm{Y})$ & Fitted value (YF) \\
\hline 1 & 23 & 119.1 & 122.816 \\
\hline 2 & 13 & 215.5 & 223.316 \\
\hline 3 & 19 & 88.56 & 96.376 \\
\hline 4 & 5 & 263.6 & 266.436 \\
\hline 5 & 24 & 109.9 & 112.736 \\
\hline 6 & 14 & 123.8 & 119.096 \\
\hline 7 & 3 & 270.4 & 260.736 \\
\hline 8 & 2 & 293.1 & 288.396 \\
\hline 9 & 1 & 226.8 & 234.616 \\
\hline 10 & 22 & 121.2 & 111.536 \\
\hline 11 & 8 & 206.7 & 201.996 \\
\hline 12 & 17 & 135.3 & 139.016 \\
\hline 13 & 7 & 193.8 & 201.616 \\
\hline 14 & 25 & 92.24 & 100.056 \\
\hline 15 & 11 & 158.5 & 162.216 \\
\hline 16 & 16 & 186 & 176.336 \\
\hline 17 & 18 & 132.1 & 134.936 \\
\hline 18 & 21 & 129 & 124.296 \\
\hline 19 & 12 & 149.7 & 152.536 \\
\hline 20 & 10 & 194.8 & 198.516 \\
\hline 21 & 6 & 186.5 & 189.336 \\
\hline 22 & 15 & 147.3 & 137.636 \\
\hline 23 & 4 & 229.7 & 233.416 \\
\hline 24 & 20 & 126.9 & 122.196 \\
\hline 25 & 9 & 179.4 & 169.736 \\
\hline
\end{tabular}

In contrast, the $P$-value is the probability value that is determined from the $F$-distribution curve. With a known degree of freedom of a factor and the residual for a given $F$-statistic, the $P$-value of that factor can be determined. The lowest $P$ value implies that the factor has the highest level of significance to the output response. From the ANOVA table, the level of significance in the ascending order is the number of spokes, depth of spokes, rib thickness, rib fillet radius, and hollow shaft thickness. This means that the hollow shaft thickness affects the torsional stress of the shaft the most in comparison to the other four factors. The regression information indicates the level of error.

Finally, a diagnostic analysis is carried out as shown in Table 5. The one highlighted is the optimum design parameters in which the actual value corresponds to the lowest torsional stress, whereas the highlighted run order \#8 corresponds to the highest actual value of the torsional stress. Therefore, the standard order 25 is the optimum set of parameter for the hollow shaft with rib in which the hollow shaft thickness is $4 \mathrm{~mm}$, rib thickness is $4 \mathrm{~mm}$, depth of spokes is 10 $\mathrm{mm}$, rib fillet is $2 \mathrm{~mm}$, and the number of spokes is 4. In addition, the fitted value (YF) is the prediction value that is dependent upon the actual value. The YF is calculated based on the equation: Fitted value (YF) $=$ Actual value $(\mathrm{Y})-$ Residual .

\subsection{Strength and Weight Comparison of the Optimized Shaft Model}

The optimized shaft is compared with the benchmark shaft, hollow shaft, and solid shaft with regard to the torsional stress and weight reduction. The torsional stress and the weight of four different shafts are obtained by FEA simulation. Table 6 shows the torsional stress and weight reduction comparisons between the four types of shaft. The weight reduction is calculated by comparing with the mass of the solid shaft which is the heaviest.

From the shaft comparisons, the optimized shaft has lower torsional stress compared to the benchmark shaft and the hollow shaft. The weight of the shaft is measured using ANSYS software to determine the percentage of weight reduction. The hollow shaft is the lightest, thus having the highest weight reduction. In order to evaluate the shaft with overall most improved strength and amount of weight reduction, the stress-to-weight reduction ratio is calculated for each shaft. The optimized shaft has the lowest stress- 
Table 6. Shaft models comparison in strength and weight reduction

\begin{tabular}{|c|c|c|c|c|}
\hline & $\begin{array}{l}\text { Optimized } \\
\text { shaft }\end{array}$ & $\begin{array}{l}\text { Benchmark } \\
\text { shaft }\end{array}$ & $\begin{array}{l}\text { Hollow } \\
\text { shaft }\end{array}$ & $\begin{array}{l}\text { Solid } \\
\text { shaft }\end{array}$ \\
\hline Length [mm] & \multicolumn{4}{|c|}{210} \\
\hline Diameter [mm] & \multicolumn{4}{|c|}{37} \\
\hline Material & \multicolumn{4}{|c|}{$\begin{array}{l}\text { AISI } 4340 \text { alloy steel } \\
\text { (normalized at } 870^{\circ} \mathrm{C} \text { ) }\end{array}$} \\
\hline Torque [Nm] & \multicolumn{4}{|c|}{100} \\
\hline $\begin{array}{l}\text { Hollow shaft thickness } \\
\text { [mm] }\end{array}$ & 4 & 3 & 3 & - \\
\hline Rib thickness [mm] & 4 & 3 & - & - \\
\hline Depth of spokes [mm] & 10 & 15 & - & - \\
\hline Rib fillet radius [mm] & 2 & 1.5 & - & - \\
\hline Number of spokes & 4 & 4 & - & - \\
\hline Torsional stress [MPa] & 88.56 & 102.70 & 141.76 & 81.28 \\
\hline Weight [kg] & 0.744 & 0.595 & 0.552 & 1.796 \\
\hline $\begin{array}{l}\text { Weight reduction [kg] } \\
\text { compared to solid shaft }\end{array}$ & 1.052 & 1.201 & 1.244 & - \\
\hline $\begin{array}{l}\text { Stress-to-weight } \\
\text { reduction ratio }\end{array}$ & 84.18 & 85.51 & 113.96 & - \\
\hline
\end{tabular}

to-weight reduction compared to the benchmark shaft and hollow shaft, which indicates it has most significant improvement in both torsional strength and weight reduction. The optimized shaft has an improved strength by $13.77 \%$ but an increase of $20 \%$ in weight compared to the benchmark model.

\section{CONCLUSION}

The shaft models were modelled using FEA and validated through comparisons with the experimental results. In the analysis of the output shaft of the portal axle, the hollow shaft with a rib is proposed and the final element model is built. The optimum set of parameters of the hollow shaft with a rib is determined by using the Taguchi method: the hollow shaft thickness is $4 \mathrm{~mm}$, rib thickness is $4 \mathrm{~mm}$, depth of spokes is $10 \mathrm{~mm}$, rib fillet radius is $2 \mathrm{~mm}$, and the number of spokes is 4 . It is found that the hollow shaft thickness affects the torsional strength of the hollow shaft with a rib the most compared to the other four parameters. The optimized shaft has an improvement in strength of $13.77 \%$ but an increase of $20 \%$ in weight compared to the benchmark shaft.

\section{ACKNOWLEDGEMENT}

The authors would like to thanks the Centre for Vehicular Technology, Universiti Tunku Abdul Rahman and the Department of Mechanical Engineering, Tunku Abdul Rahman College for the facilities and system supports.

\section{REFERENCES}

[1] Xu, X.L., Yu, Z.W., Ding, H.X. (2006). Failure analysis of a diesel engine gear-shaft. Engineering Failure Analysis, vol. 13, no. 8, p. 1351-1357, DOI:10.1016/j. engfailanal.2005.10.015.

[2] Heisler, H. (1999). Vehicle and Engine technology. 2nd ed. SAE International, London.

[3] Heyes, A.M. (1998). Automotive component failures. Engineering Failure Analysis, vol. 5, no. 2, p. 129-141, DOI:10.1016/S1350-6307(98)00010-7.

[4] Vogwell, J. (1998). Analysis of a vehicle wheel shaft failure. Engineering Failure Analysis, vol. 5, no. 4 p. 271-277, DOI:10.1016/S1350-6307(98)00022-3.

[5] Yüksel, C., Kahraman, A. (2004). Dynamic tooth loads of planetary gear sets having tooth wear. Mechanical Machine Theory, vol. 39, no. 7, p. 695715, DOI:10.1016/j.mechmachtheory.2004.03.001.

[6] Ranganath, V.R., Das, G., Tarafder, S., Das, S.K. (2004). Failure of a swing pinion shaft of a dragline. Engineering Failure Analysis, vol. 11, p. 599-604, DOI:10.1016/j.engfailanal.2003.08.004.

[7] Shigley, J.E., Mischke, C.R. (1989). Mechanical Engineering Design, $5^{\text {th }}$ ed. McGraw Hill Publication, New York.

[8] ANSI/ASME Standard B106.1M-1985 (1985). Design of Transmission Shafting. American Society of Mechanical Engineers, New York.

[9] Spotts, M.F. (1991). Design of Machine Elements, 6th ed. Prentice Hall India, New Delhi.

[10] Opalić, M., Kranjčević, N., Habuš, S. (2011). Proof of strength of shafts and axles using finite element method. FAMENA, vol. 35, no. 2, p. 63-71.

[11] Ooi, J.B., Wang, X., Tan, C.S., Ho, J.H., Lim, Y.P. (2012). Modal and stress analysis of gear train design in portal axle using finite element modeling and simulation. Journal of Mechanical Science and Technology, vol. 26, no. 2, p. 575-589, DOI:10.1007/ s12206-011-1040-5.

[12] Göksenli, A., Eryürek, I.B. (2009). Failure analysis of an elevator drive shaft. Engineering Failure Analysis, vol. 16, no. 4, p. 1011-1019, DOI:10.1016/j. engfailanal.2008.05.014.

[13] Bayrakceken, H., Tasgetiren, H., Yavuz, I. (2007). Two cases of failure in the power transmission system on vehicles: A universal joint yoke and a drive shaft. Engineering Failure Analysis, vol. 14, no. 4, p. 716724, DOI:10.1016/j.engfailanal.2006.03.003.

[14] Vijay Sekar K.S., Pradeep Kumar, M. (2012). Optimising Flow Stress Input for Machining Simulations Using Taguchi Methodology. International Journal of Simulation Modelling, vol. 11, no. 1, p. 1728, DOI:10.2507/IJSIMM11(1)2.195. 